\title{
How (often) do voters change their consideration sets?
}

\author{
Roderik Rekker \\ University of Amsterdam \\ r.rekker@uva.nl
}

\author{
Martin Rosema \\ University of Twente \\ m.rosema@utwente.nl
}

Draft version of: Rekker, Roderik, \& Martin Rosema (2018). How (often) do voters change their consideration sets? Electoral Studies.

\begin{abstract}
The consideration set model posits that in multi-party elections voters decide in two stages. We expect that in the consideration stage, when voters select viable options, ideological proximity is a key determinant, while in the choice stage election-specific factors become particularly important. This would imply that consideration sets are rather stable and that changes in voting preferences occur mainly within ideologically coherent consideration sets. This study examines both claims by analyzing panel survey data from Sweden and the Netherlands. Consideration sets were indeed rather stable, more so than voting intentions. After one year, voters still considered the same party in $81 \%$ of cases and only $13 \%$ of respondents shifted between ideological camps. This indicates that voters changed electoral preferences primarily within the boundaries of relatively stable consideration sets and ideological camps. These findings help to understand how elections can be volatile, despite the strong impact of highly stable ideological orientations.
\end{abstract}

Keywords: voting behaviour, consideration set, electoral volatility, attitude stability 


\section{INTRODUCTION}

Consideration set models appear to be gaining momentum in research on voting behaviour. These models posit that if people make a choice from a number of alternative options, they first screen the alternatives and identify a small number of viable options that form the consideration set, while in the second stage they make a choice from within this set. This model was originally developed for the study of consumer choice, but has also been proposed for the analysis of voter decision making (Oscarsson \& Rosema, this issue). Because this kind of phased decision making is most likely when the number of choice options is large, consideration set models are particularly relevant for multi-candidate and multi-party elections. Indeed, several studies show that applying these models in such contexts leads to valuable insights (e.g., Wilson, 2008; Karlsen \& Aardal, 2016; Oskarson et al., 2016; Schmitt-Beck \& Partheymüller, 2016; Vassik et al., 2016; Moral \& Zhirnov, 2018). Given the novelty of this approach in electoral research, obviously many pivotal questions about voters' consideration sets are still unanswered. The symposium in this journal brings together papers that address some of them, in order to further explore the value of consideration set models for the study of voting. In our paper we contribute by focusing on two fundamental questions, which did not yet receive much attention in the emerging literature. These questions are how stable voters' consideration sets are and if they change, in what ways they do. In other words, we explore how often voters form and change consideration sets, and if they modify them, whether those changes follow predictable patterns.

One reason that analysing this is interesting, is because it can shed light on a paradox in electoral research. Numerous studies have provided evidence for two observations that seem at odds with each other. On the one hand, research has shown that in the past decades electoral volatility has strongly increased and reached high levels (Drummond, 2006; Dassonneville \& Hooghe, 2011). This suggests that citizens' vote preferences are not very stable. On the other hand, numerous studies have shown that vote preferences are strongly shaped by the ideological match between voters and parties, while ideological positions are rather stable (Van der Eijk et al., 2005; Rekker et al., 2015). This could lead one to expect that vote preferences must, in turn, also be rather stable. An analysis of voters' consideration sets may synthesize both findings into one perspective: in theory, it is well possible that many voters always consider the same subset of ideologically related political parties as serious options, but shift their first preference within this subset in response to election-specific factors. In that case, their electoral preferences are more stable than high levels of electoral volatility might suggest: under the surface of unstable electoral choices are more stable consideration sets of two or more parties. 
This view is not completely at odds with past electoral research, because numerous studies have shown that especially in multi-party systems having positive feelings towards one party, does not exclude the possibility of also being positive about other parties (Van der Eijk \& Franklin, 1996; Rosema, 2014; Mayer \& Schultze, 2018). Furthermore, those same studies demonstrate that political parties that are evaluated positively by the same voter usually have a similar ideological profile, either in terms of their left/right position or in terms of other factors that structure party competition and electoral support (e.g. cleavage structure). What is not yet known, however, is how this translates into consideration sets of voters. This paper therefore explores in two countries with a multi-party system and for which suitable data are available (Sweden and the Netherlands), how many voters formed consideration sets, how stable these consideration sets were across time, and to what extent changes in consideration sets occurred within boundaries related to their ideological profiles.

In the next section we elaborate on the theoretical foundations of the consideration set model and its application to voting behaviour, focusing in particular on the stability of electoral consideration sets and the nature of changes. The method section that follows describes the data and measures from Swedish and Dutch surveys that we utilize, as well as our analytical strategy. Next we present the results, exploring first the stability of consideration sets and then the patterns in the changes. We end our contribution with a general discussion of the findings.

\section{THEORY}

\subsection{A two-stage model of vote choice}

The introduction to this journal's symposium about consideration set models of electoral choice elaborately discusses the theoretical foundations of these models, as well as their applications to vote choice (Oscarsson \& Rosema, this issue). In this section, we therefore only provide a brief summary and highlight some elements.

The concept of consideration sets stems from a model of phased decision making that is commonly used in consumer research (Roberts \& Lattin, 1991, 1997; Shocker et al., 1991). It builds on earlier psychological theories of consumer choice (Howard \& Sheth, 1969) and decision making more generally (e.g., Simon, 1955; Tversky, 1972). According to the consideration set model, when consumers are faced with a purchase decision, they narrow down the available options in subsequent phases until they make their choice. They first develop an awareness set with all available choice options that they know of. Next, they form a 
consideration set with a limited number of attractive alternatives that they regard as viable choice options, which they may narrow down in one or more steps into a smaller set (sometimes labelled choice set). In the last step they make their final choice from within this set of viable options.

Studies that applied this model to voting behaviour typically ignored the awareness set, as well as the distinction between consideration set and choice set. Consequently, two phases in the vote choice process are distinguished: a consideration stage, in which voters select one or more viable alternatives from the available options (e.g., all competing political parties or candidates), and a choice stage, in which they select one party (or candidate) from within the consideration set (see e.g., Karlsen \& Aardal, 2016; Oskarson et al., 2016; Schmitt-Beck \& Partheymüller, 2016). Some voters may regard only one party or candidate as a serious option and then the consideration set is identical to the final choice. Many voters, however, at some point in the campaign period hesitate between two or more parties and for them in particular consideration sets appear to be a useful concept to describe and analyse the choice process. Please notice that consideration set models focus on choice situations where people have to select one option. In most elections this is indeed the type of choice required by the ballot structure, although exceptions exit - for example, in some elections voters have to list candidates in the order of their preference - and here consideration set models may be less valuable.

An interesting aspect of consideration set models is that in both phases consumers and voters can be influenced by different factors (Gensch, 1987; Karlsen \& Aardal, 2016). On the basis of the large body of prior research on electoral behaviour (see, e.g. Thomassen, 2005; Van der Eijk \& Franklin, 2009), we expect core political orientations such as left/right position to be the main structuring factor that shapes the composition of electoral consideration sets. For the choice from within these consideration sets, short-term factors such as leader evaluations and strategic considerations can be decisive. This view matches with findings from some early research on consideration sets and voting. For example, the most common combinations of parties in consideration sets among Dutch voters in 2010 were often sets of left-wing parties or sets of right-wing parties (Rosema, 2015, p. 33). Furthermore, those same voters appeared to use different criteria in the consideration stage than in the choice stage, or put different weight on the same criteria in both stages (De Vries \& Rosema, 2009). Positions on three key policy dimensions were found to play a stronger role in the consideration stage than in the choice stage. Reversely, leader evaluations appeared more important in the choice stage than in the consideration stage. Focusing on Norway, another study found that core political values had a 
strong impact on the composition of consideration sets, while campaign factors such as issue ownership influenced the final choice from within this set (Karlsen \& Aardal, 2016). In brief, several studies lend support to the ideas that consideration sets exist, that different factors may have an impact in both stages of the choice process, and that core political orientations shape the composition of consideration sets, while election-specific factors have a strong impact on the choice from within this set. The topic of specific factors being especially relevant in either stage is explored further in other contributions to this symposium (Fredén \& Sohlberg, this issue; Oscarsson \& Oskarson, this issue; Steinbrecher \& Schoen, this issue).

\subsection{The stability of voters' consideration sets}

The finding that voters are influenced most strongly by different factors in the consideration stage than in the choice stage, has important implications for the over-time stability of consideration sets and voting behaviour. The factors that seemingly influence voters most strongly during the consideration stage, such as left-right positions and policy preferences, are part of voters' core political orientations and these are highly stable across a life span (e.g., Jennings \& Markus, 1984; Alwin et al., 1991; Sears \& Funk, 1999). For instance, a study among Dutch voters showed that the stability across six years was rather strong for attitudes towards redistribution, a symbol of the socio-economic left-right dimension, as well as for attitudes towards multiculturalism, a symbol of the cultural dimension (over-time correlation coefficients equalled 0.57 and 0.69, respectively; Rekker et al., 2015). Left-right selfclassification in the same period was also rather stable, as only one out of ten voters moved from the left to the right or vice versa (over-time correlation coefficient equalled 0.59; Rekker et al., 2018). Likewise, an American study found strong stability across a 17-year period for party identification (over-time correlation coefficient equalled 0.72; Sears \& Funk, 1999). Research on youths shows that stable political orientations can be traced back to a formative period during adolescence and early adulthood (e.g., Rekker et al., 2015, 2018; Rekker, 2016).

If voters form consideration sets based on rather stable political orientations, like left/right position, it seems likely that this will result in consideration sets that are also highly stable. The factors that influence voters during the choice stage, on the other hand, are presumably more changeable over time. For example, the popularity of a party's leader commonly changes from one election to the next, or even within an election campaign due to media performances (e.g., Kleinnijenhuis et al., 2001). Likewise, voters may make different strategic choices in subsequent elections, for instance related to coalition formation or parties' 
chance to surpass an electoral threshold in that specific election (e.g., Blais \& Nadeau, 1996; Fredén \& Sohlberg, this issue). If voters make their eventual choice based on such changeable factors, it seems likely that this will result in relatively unstable voting intentions and voting behaviour despite the existence of stable consideration sets.

\section{[ FIGURE 1 ABOUT HERE ]}

Based on this reasoning, Figure 1 depicts a two-stage model of electoral choice that summarizes the hypothesized formation and stability of electoral consideration sets and voting intentions. In the consideration stage, voters form a consideration set of one or more parties that match their core political orientations, such as the ideological position. In the choice stage, voters form a voting intention that favours one of the political parties in the consideration set under influence of election-specific factors like media coverage of the campaign, leader evaluations, and strategic considerations. If consideration sets are strongly based on voters' core political orientations, which are known to be rather stable, while voting intentions are influenced by less stable factors related to the election campaign, we should be able to observe that consideration sets are fairly stable, and more so than voting intentions. In this study we aim to examine if that is true, and to what extent such shifts occur. Hence, our first research question is: How often do voters change their consideration sets as compared to their voting intentions? In light of the above discussion, we hypothesize the following: (H1) Voters more often change their voting intention than change a party in their consideration set. We should add that such chances are also affected by the size of the consideration set: the larger the consideration set, the stronger the likelihood - on the basis of pure chance - that the same party will be in a consideration set at two different points in time. We should bear this in mind when interpreting the results of analyses about the stability of consideration sets and voting intentions.

\subsection{A nested hierarchy}

If consideration sets are relatively stable over time, the question still remains what the changes in the composition look like if they do occur. As argued above, we expect that changes in consideration sets occur mainly when voters supplement their consideration set with a party that is ideologically close to the parties that they already considered, or reversely stop considering one option from a block of ideologically related parties. This pattern matches the changes that have been observed in voting behaviour at the individual level, where voters 
mostly switched either between left-wing parties or between right-wing parties (e.g. Van der Meer et al., 2012, 2015). It also matches with the affective evaluations of political parties: combinations of parties that were rated equally favourably often comprised either a set of leftwing parties or a set of right-wing parties (Rosema, 2004, p. 121). If changes in consideration sets would primarily occur within the boundaries of ideological blocks of parties, this implies that voting intentions, consideration sets, and ideological blocks are structured according to a nested hierarchy in which each changes within the boundaries of the other. This idea can be illustrated by the example of a voter who would fit the structure perfectly: a certain woman who developed leftist values and a leftist identity during her early life may during her entire life span only consider leftist parties, which can be regarded as making up a stable ideological block. Which leftist parties she considers may change occasionally across elections, as reflected by an intermediately stable consideration set. Which of the considered parties she decides to vote for might change more frequently based on election specific factors, resulting in a relatively unstable voting intention and voting behaviour.

In electoral research voters are often divided between partisans and non-partisans, while partisans in turn are divided into segments on the basis of the political party that they are attached to. In the United States this resulted in the well-known classification of the electorate into Democrats, Republicans and Independents (Campbell et al., 1960). Even though a more fine-grained classification is possible, namely by incorporating the strength of partisan attachments and the 'leaning' towards a particular party by independents, the most fundamental classification remains those three categories (Miller, 1991). For the classification of voters on the basis of their consideration sets, this approach is not appropriate, because it regards partisan attachments as mutually exclusive. If voters form consideration sets and if these are mostly composed of political parties with a similar ideological profile, it should be possible to meaningfully distinguish groups of voters on the basis of their consideration sets. To refer to such groups of voters we take inspiration from Mayer and Schultze (2018) and use the term ideological camps. The parties that are often considered together and which have a relatively similar ideological profiles, we label ideological blocks. Please note that this does not require any formal electoral alliance among parties; we use the term merely to refer to a group of political parties that are ideologically relatively similar and frequently combined in voters' consideration sets. It is possible that a specific party is part of two ideological blocks and considered by voters from different ideological camps. For instance, if an electorate is divided into one segment of left-wing voters and another segment of right-wing voters, a centrist 
political party might be a viable option for some left-wing voters as well as for some right-wing voters.

In light of these ideas, the second research question is: To what extent do changes in voting intentions and changes in the composition of consideration sets occur within the boundaries of such a nested hierarchy? If the nested hierarchy applies, two additional hypotheses need to be confirmed. One hypothesis concerns to which political party voters shift if they change their voting intention: (H2) Voters who change their voting intention are more likely to favour a party that was included in a prior consideration set than any of the other parties. Because the size of consideration sets is typically limited (see Table 1), on the basis of pure chance voters would be more likely to shift to a party outside the prior consideration set. But if the nested hierarchy applies, the parties in the prior consideration set are the most likely options to shift to. The next hypothesis concerns shifts in consideration sets: (H3) Voters who change their consideration set are more likely to keep favouring parties from the same ideological block than to switch to parties from another ideological block. Phrased in the terminology of the corresponding ideological camps, this means that even if voters change their consideration sets they are expected, in the majority of cases, to keep fitting the same ideological segment of the electorate (as revealed by their consideration sets). Obviously, the question also arises what those ideological blocks and ideological camps look like, i.e. which political parties are considered together. In the light of the previous discussion, one may expect that a camp of voters favouring left-wing parties and a camp of voters favouring right-wing parties will be identifiable in most Western democracies. However, country differences are well possible regarding the size of both those camps, as well as with respect to the number and size of potential additional ideological camps that may exist.

\section{METHOD}

\subsection{Case selection}

To explore the stability of consideration sets and the patterns of changes, this study utilizes panel survey data from Sweden and the Netherlands. Both countries have a multi-party system (Lijphart, 2012, chap. 5), which makes them suitable for the application of consideration set models (Oscarsson \& Rosema, this issue). Furthermore, the level of electoral volatility makes them relevant cases. Sweden is a typical case, because its volatility is average compared to other West European countries (Dassonneville \& Hooghe, 2011). Volatility in the Netherlands, on 
the other hand, ranks among the highest of all established democracies (Mair, 2008). Since we are interested in the potential stability behind electoral volatility, we do not focus on countries where electoral volatility is low. Moreover, such countries often have a two-party system, for which consideration set models have less to offer. Sweden was selected also because there is presumably no other country for which more extensive and suitable data about electoral consideration sets are available, in large part due to the pioneering work by Oscarsson and his colleagues (Oscarsson et al., 1997; Oskarson et al., 2016). The availability of panel data about consideration sets is also another reason to include the Netherlands.

\subsection{Data}

The Swedish data are from the 2014 Consideration Set Model Campaign Panel Study (Boije et al., 2016). Respondents were recruited mainly through self-selection using online advertisements $(N=17.516)$ and partly through probability sampling $(N=2.053)$. The survey comprised nine waves of data collection through web-based questionnaires carried out under supervision of scholars at the University of Gothenburg. Our analyses make use of the first wave in March 2014 and the last wave in February 2015 (from here referred to as second wave), spanning a time period of about one year. Two elections were held in Sweden in this period: the European Parliament election in May 2014 and the Swedish general election in September 2014. During the first wave, 19.569 respondents participated, while 12.307 respondents participated again in the second wave.

Surveys that rely on self-recruitment tend to have a biased sample of the population and this study is no exception: the panel includes relatively many male, young, and highly educated voters. Furthermore, nearly all respondents (96\%) stated that they were rather or very interested in politics, as opposed to just over half (57\%) of the population at large (Boije et al., 2016). This selective response, however, does not appear to have altered the results of the below analysis in any meaningful way, since a replication (findings not reported here) of the analyses using only the probability sample revealed nearly identical results.

The Dutch data consist of survey data of two waves of self-administered online questionnaires from an ongoing panel study of $I \& O$ Research, a company that is specialized in research focusing on the public sector. The respondents $(\mathrm{N}=5.054)$ participated in two waves: a first wave in February/March 2015 and a second wave in April 2016, so also covering a time span of about one year. Shortly after the first wave, provincial elections were held on 18 March 2015. Provincial elections in the Netherlands have a quasi-national character, because they 
determine the composition of the upper house of the parliament, but the campaign intensity is much weaker than for lower house elections. Most panel members were recruited throughout the years via probability sampling, but due to selective nonresponse and panel attrition substantial biases occurred: highly educated, politically engaged, and male voters were present in larger numbers. This bias was less pronounced, however, than in the Swedish sample, as illustrated by the fact that 'only' 65 percent of the Dutch respondents indicated that they were fairly or very interested in politics.

The period that we focus on, approximately one year in both countries, is limited. Selfevidently, it would be interesting to expand the time span, preferably across several election cycles. However, to the best of our knowledge survey data spanning several elections with suitable measures for consideration sets are not yet available. So instead of being very patient and wait until such data are available, we make a modest contribution by focusing on a oneyear period. Although this does not enable us to draw firm conclusions about the long-term stability of consideration sets, it does enable us to compare the stability of consideration sets with voting intentions and also to analyse the patterns that occur if voters do change those sets.

\subsection{Measures}

In both surveys consideration sets were measured by directly asking voters about them, as recommended in the symposium introduction (Oscarsson \& Rosema, this issue). In Sweden, the following question was used: "Which party or parties would you consider voting for in a parliamentary election? Keep in mind that more than one answer is possible!" Respondents chose from a list of all participating parties. We regard the parties selected as the consideration set and the number of parties selected as the consideration set size. To facilitate the analyses, only the nine political parties that were mentioned by at least three percent of respondents in both waves are included in our analysis. Voting intentions were assessed using a common question in public opinion research: "Which party would you vote for if parliamentary elections were held today?"

The questions in the Dutch survey differ from the Swedish survey and follow a stepwise procedure adapted from the Dutch Parliamentary Election Studies. Respondents were first asked which party they intended to vote for in the next parliamentary election. Those who mentioned a party were subsequently asked which other parties that they also considered to vote for, if any. Respondents who expressed no voting intention at the initial question, were asked if there were parties that they considered to vote for, and which. For these follow-up 
questions people could list as many parties as they wanted. We define the consideration set as all parties mentioned in response to any of the aforementioned survey questions. We limit our analysis to the eleven parties that had at least one seat in the Lower House of the Dutch Parliament (Tweede Kamer). In the second wave the final item was not administered for respondents who did not yet know for which party they would vote, and consequently we lack information on consideration sets for 15 percent of this wave's respondents.

The stability of voting intentions is determined in a straightforward manner: of all respondents who reported a voting intention in both waves, we calculate what percentage reported the same party again in the second wave. Likewise, we calculate for each voter what percentage of the parties that were considered in the first wave, were still considered in the second wave. In other words, these two estimates indicate respectively the probability that a voter still intended to vote for the same party after one year and the probability that a voter still considered a certain party if it was included in the consideration set one year earlier. To test the hypothesis that consideration sets are more stable than voting intentions, we compare both measures using a formula for the comparison of parameter estimates (Paternoster et al., 1998). ${ }^{1}$

\subsection{Strategy of analysis}

To analyse the composition of consideration sets, as well as the nature of changes in those compositions, at least two different approaches are possible. One is to identify ideological blocks a priori as researcher, by grouping together political parties on the basis of information such as manifesto coding or expert ratings, and then analyse the composition and shifts in relation to the pre-defined blocks of parties. A second possibility is to take the consideration sets as a starting point and define no party blocks in advance, but analyse the structure of those consideration sets by distinguishing groups of voters with similar consideration sets. If longitudinal data are available, such an analysis can also take changes into account. An advantage of the second approach is that it enables researchers to systematically and inductively uncover structures in the composition of consideration sets, and changes in these across time, of any nature - so also those that do not match with any specific hypothesized structure.

We choose the second option and introduce an approach that classifies voters in latent classes on the basis of their consideration sets. We expect that the electorate can be divided into a small number of segments, each of which comprise voters who consider political parties that

${ }^{1} Z=\frac{b 1-b 2}{\sqrt{S E b 1^{2}+S E b 2^{2}}}$ 
are ideologically related. In latent class analysis (LCA) voters with consideration sets that show most overlap are grouped together and referred to as ideological camps, assuming that parties that are frequently considered together will be ideologically similar. It is possible that some parties are frequently considered together with parties from more than one ideological block and the analysis allows for this. If longitudinal data are used, changes in consideration sets can be analysed to identify if voters remained in the same latent class or ideological camp, or switched.

To model the latent classes, we use latent transition analysis (LTA) with robust maximum likelihood estimation (MLR). LTA is an extension of LCA for panel data (Kaplan, 2008). The basis for this are dichotomous variables that indicate for each political party if a voter considered it or not at that time, i.e. either in the first wave or in the second wave. Like in LCA, LTA models assign a class membership to every respondent by using class-specific parameters (i.e., scores on whether or not parties are considered) as measurement parameters, and class probabilities as structural parameters. To ensure that classes have the same meaning over time, the measurement model is constrained to be equal across waves. The model can therefore estimate latent transition probabilities, which indicate respondents' probability of moving from one class to another over time. Because we are primarily interested in estimating and comparing stability in general rather than specific patterns of change, this study examines change and stability using class memberships themselves (in a similar way as for voting intentions), instead of using the latent transition probabilities.

We determine the number of ideological camps by specifying models with an increasing number of classes. We examine if adding a class improves the classification with three criteria. First, we determine if adding another class significantly improves the ability to capture all consideration sets with the Vuong-Lo-Mendell-Rubin (VLMR) test. Because this test is not available for LTA models, we perform this test in a regular LCA with the first wave. Second, we determine if adding another class results in a lower value of the sample adjusted Bayesian Information Criterion (BIC). Third, we examine what number of classes provides the best entropy, which is a standardized measure of classification (Reinecke, 2006).

To examine the hypothesized nested hierarchy, we analyse what percentage of respondents have consideration sets in the second wave that match with the ideological camp that they fitted in the first wave. Likewise, we investigate what percentage of respondents' voting intentions in the second wave were already part of their consideration set in the first wave. As such, we examine if changes in consideration sets occur mostly within the boundaries of ideological camps and if changes in voting intentions occur primarily within the boundaries 
of consideration sets. To complete the picture, we examine what percentage of respondents' voting intentions in the second wave fit their ideological camp in the first wave.

\section{RESULTS}

\subsection{Stability and change}

Table 1 shows how many parties voters included in their consideration set in the first wave, as well as how many parties received the same response (being considered again by the same voters) in the second wave. In Sweden about one out of every three voters (31\%) reported only one political party - and hence had a consideration set size of one - whereas in the Netherlands a majority (56\%) of the voters considered only one political party. This suggests that Dutch voters were more often decided about for which party to vote, but the difference may also be a methodological artefact stemming from differences in question wording: the Swedish item explicitly stated that people could mention more than one party and this may have stimulated them more strongly to report two or more parties than the Dutch items. Among Swedish voters it was fairly common to consider two or three parties, and occasionally more, leading to an average of 2.0 parties in the consideration set. Dutch respondents typically considered one or two parties, but sometimes more, leading to an average of 1.4 parties. These figures suggest that consideration sets, which are most relevant if they include at least two parties, are certainly not important for the whole electorate all of the time. Nevertheless, the proportion of voters who appear to have formed consideration sets is certainly large enough to merit serious attention in electoral research.

\section{[ TABLE 1 ABOUT HERE ]}

Swedish respondents typically gave the same response in both waves for either seven, eight, or all of the nine parties, with an average of 7.9 parties (out of 9). So people reporting consideration sets of two or more parties and changing these sets completely, seldom occurred. Most Dutch respondents gave the same response for nine, ten, or all of the eleven parties, with an average of 10.2 parties (out of 11). Figure 2 depicts the stability of the composition of the consideration sets in more detail. It shows that between one third and half of the voters had a fully stable consideration set (white area), while only two to three out of ten voters changed more than one party in the consideration set (dark grey and black area). If voters would choose 
parties at random, these figures would self-evidently be much lower and the chance that they would have identical or overlapping consideration sets would be rather small. So consideration sets showed a fair amount of stability across the one year period that we examine.

\section{[ FIGURE 2 ABOUT HERE ]}

To compare the stability of consideration sets and voting intentions and find out if the former are more stable than the latter $(\mathrm{H} 1)$, we first calculate the stability of voting intentions. Of all respondents who indicated a voting intention in the first wave, $67.6 \%$ of Swedish respondents and $82.7 \%$ of Dutch respondents still intended to vote for the same party in the second wave (see Table 2). Next we calculate the percentage that still considered a particular party in the second wave, if it had been included in the consideration set in the first wave. When Swedish respondents considered a party in the first wave, they still considered that same party the year after in $73.1 \%$ of cases. For Dutch respondents, this percentage was $87.9 \%$. As we expected, a statistical comparison between both estimates shows that consideration sets were indeed more stable than voting intentions (Sweden: $\Delta=5.5 \%, p<.001$; Netherlands: $\Delta=5.2 \%$, $p<.001)$. Averaged between Sweden and the Netherlands, the stability was $75.2 \%$ for voting intentions and $80.5 \%$ for parties in consideration sets. Self-evidently, the chance that voters' consideration sets are fully identical in both waves is smaller, and only a minority (36.9\% in Sweden; $46.2 \%$ in the Netherlands) of the voters did not make any change in their consideration set (i.e., same size, identical composition) when focusing on all parties in the set jointly.

\section{[ TABLE 2 ABOUT HERE ]}

\subsection{Ideological camps}

To examine if consideration sets changed mainly within ideological camps, we classify voters' consideration sets into latent classes of commonly occurring combinations. To this end, we first determine the optimal number of classes in a latent transition analysis (LTA). We compare LTA models with up to five classes (see Table 3). For Sweden, we conclude that the optimal solution is a model with three latent classes. Although the VLMR test reveals a significantly improved prediction for each of the five classes, the BIC decreases only very modestly by adding a fourth or a fifth class. Most importantly, the three-class solution is the only model with a good entropy (Reinecke, 2006). For the Netherlands, we conclude that the optimal solution is a model with 
four latent classes. The VLMR test reveals a significantly improved prediction for each of the five classes, but the BIC decreases only modestly by adding a fifth class. Moreover, the fourclass solution reveals the best entropy value for the Netherlands.

\section{[ TABLE 3 ABOUT HERE ]}

When inspecting the classification for Sweden, three distinct latent classes or ideological camps become apparent (see Figure 3). A first ideological camp consisted of leftist voters who mostly considered some combination of the Left Party, Social Democrats, Green Party, and Feminist Initiative. Notice that we label these voters as leftist voters on the basis of the parties that they included in their consideration sets, and not on the basis of any other information (e.g. left/right self-placement or policy preferences); likewise, labels of other ideological camps used below are derived solely from the parties most often included in the consideration sets of the voters grouped together in the latent class analysis. A second ideological camp was made up of rightist voters who considered some combination of the Moderates, Peoples Liberal Party, Christian Democrats, and Centre Party. Interestingly, voters who considered the Sweden Democrats, a populist radical right party (Jungar \& Jupskås, 2014), were mostly classified in a separate class. This indicates that sympathizers of the Sweden Democrats were relatively unlikely to also consider other parties. Specifically, $44.5 \%$ of the voters who considered the Sweden Democrats did not consider any other party, and the remainder were spread out relatively equally across leftist and rightist parties. These findings illustrate that consideration sets can also be used to analyse the nature of electoral competition (see also Steenbergen \& Willi, this issue).

\section{[ FIGURE 3 ABOUT HERE ]}

\section{[ FIGURE 4 ABOUT HERE ]}

When inspecting the classification for the Netherlands, four ideological camps become apparent (see Figure 4). The first camp comprises leftist voters who often considered the Socialist Party, Green Left, Animal Party, Labour Party (PvdA), and Democrats 66 (D66). The second class comprised voters who mainly considered one or more Christian parties - Christian Democratic Appeal (CDA), Christian Union, and Reformed Political Party (SGP). Rightist voters, who usually considered the People's Party for Freedom and Democracy (VVD) - which 
when combined with other parties mostly involved either the Christian Democrats (CDA) or Democrats 66 - formed the third class or ideological camp. Voters who considered the Freedom Party (PVV), a Dutch populist radical right party (Rooduijn, 2014), formed a class on its own, like the Swedish Democrats. Overall, the solutions for the Netherlands and Sweden reveal similarities, with a leftist, a rightist, and a radical right or an anti-immigrant ideological camp. The main difference is a fourth group of voters in the Netherlands who are attracted to Christian parties. Furthermore, two Dutch parties were considered by more than 20 percent of the voters in two different ideological camps (Democrats 66 among left-wing and right-wing voters; Christian Democrats among Christian and right-wing voters), while in Sweden none of the parties was that popular among voters in more than one ideological camp.

To answer our second research question, we determine the stability of ideological camps as identified using LTA. Results showed that $87.0 \%$ of Swedish respondents and $86.1 \%$ of Dutch respondents were classified in the same ideological camp in both waves (see Table 2). These findings are in line with our expectation that preferences for political parties as reflected in consideration sets are highly stable over time (to facilitate the interpretation of those figures: on the basis of chance, and assuming identical numbers and sizes of ideological camps in both waves, the percentages would have been $43 \%$ for Sweden and $34 \%$ for The Netherlands). So, if voters change their consideration sets, they most of the time do so in understandable ways and remain in the same ideological camp.

\subsection{The nested structure}

In the final part of the analysis we examine the hypothesized nested hierarchy of voting intentions, consideration sets, and ideological camps. To this end, we present information in Table 4, which indicates for every party (a) how many of its supporters at the follow-up wave had a different voting intention than one year earlier, (b) what share of all voters who changed their voting intention switched to a party that they already considered one year earlier and (c) what percentage of all voters who changed their voting intention nevertheless remained within the same ideological camp. Averaged across all parties in both countries, just over one quarter of voters changed their voting intention during this one-year period. Just over half of these switchers shifted to a party that they already considered, while about three quarters of those who changed their voting intention still remained within the same ideological camp. This pattern furthermore appears to be relatively consistent across parties, with the main exceptions being three parties that more or less formed a separate class or ideological camp in the latent 
transition analysis: Sweden Democrats and the Liberal Party (VVD) and Party for Freedom (PVV) in the Netherlands (see Figure 4).

\section{[ TABLE 4 ABOUT HERE ]}

Overall, these findings confirm and illustrate the idea of a nested hierarchy in which voting intentions fluctuate mainly within the boundaries of consideration sets, which in turn change primarily within the boundaries of ideological camps. Yet, voting intentions and consideration sets are clearly not set in stone. Although across this one-year period much stability was observed (only imagine how low the numbers would have been, if voters would always choose parties randomly), in both countries about one in every ten voters preferred a party in the second wave that they did not yet include in their consideration set one year earlier; and about three out of every twenty voters had a consideration set that would put them in another ideological camp than the one they fitted the year before. Nevertheless, the general pattern is that voting intentions usually match well with pre-existing consideration sets, while consideration sets even if they change usually still match with ideological camps those voters fit in.

\section{DISCUSSION}

This study has examined the stability of consideration sets in Sweden and the Netherlands, using survey data spanning a one-year period. The results indicate that in both countries many voters (31\% in Sweden and $56 \%$ in the Netherlands) had a consideration set that comprised only one party and hence had no doubt about for which party to vote. The other voters, however, listed two or three parties as viable options and sometimes even more. So for a substantial part of the electorate in these multi-party systems a consideration set model of electoral choice appears to be an accurate description of the choice process. When analysing the changes in consideration sets, our expectation was confirmed that they would be more stable than voting intentions: across a period of about one year, on average, $81 \%$ of considered parties remained stable over time, as opposed to $75 \%$ of voting intentions.

The results of a latent transition analysis (LTA) revealed that consideration sets are clearly structured and changes follow a specific pattern. They can be adequately captured by a limited number of latent classes that we interpreted as ideological camps: a left-wing, rightwing and radical right-wing ideological camp could be identified for both Sweden and the 
Netherlands, while the latter country additionally included a separate group that comprised voters with consideration sets including Christian parties. Voters who fully or partly changed their consideration set in the one-year period of our analysis, mostly did so without moving to a different ideological camp (on average, $87 \%$ of the voters remained part of the same latent class). Finally, we found a nested hierarchy in which voters changed their voting intentions mainly within the boundaries of consideration sets, while they changed their consideration sets primarily within the boundaries of the ideological camps.

Although this study could draw from suitable panel data from Sweden and the Netherlands, some limitations have to be considered. In comparing the stability of voting intentions and consideration sets, this study faced the inevitable obstacle that both constructs lack a clear common metric. Because voters can consider multiple parties, the base-rate probability (i.e., based on random chance) that the same party is mentioned on two occasions is larger for consideration sets than for voting intentions. We however do not view this baserate stability as a statistical artefact, but rather as a substantively interesting feature of consideration sets and their over-time stability: Because voters can always keep multiple parties in mind, consideration sets have the ability to be a source of over-time continuity.

Another limitation is that the analysis covered only a relatively short time span of one year. Future studies may examine consideration sets over multiple years, or ultimately even longer periods covering multiple election cycles. This requires the inclusion of suitable questions in long-term panel surveys. How such questions are best phrased is another matter that requires scholarly attention, for example by conducting experiments about the question wording. Future research could also contribute by using data from multiple waves in a short period (e.g., one election campaign) and trace changes to smaller time intervals. When held in the run-up to real elections, such research could avoid another limitation of our study: it focuses on voting preferences reported for a hypothetical election 'today' or 'tomorrow'. So it remains to be see if in real elections the patterns are identical. Self-evidently, there are also still other ways in which future research can help to overcome the limitations of the present study, such as improving the representativeness of samples, including other countries in the analysis, or focusing on situations in which new political parties emerge on the electoral market (this can of course also influence the composition of consideration sets). In brief, the present study provides several clues regarding valuable future studies about consideration sets in electoral research.

Nevertheless, this exploratory study provides some insights in the stability of consideration sets and the structure of changes. In both Sweden and the Netherlands changes 
in consideration sets occurred mostly within the boundaries of what we have called ideological camps. Their presence is consistent with the observation that left-right is the primary long-term determinant of voting behaviour in many West-European countries (e.g., Van der Eijk \& Franklin, 1996; Tillie \& Fennema, 1998) and that most voters vote for either a leftist or a rightist party in subsequent elections (Van der Meer et al., 2015). More generally, the structuring and stabilizing effect of ideological blocks of parties that was observed in our analysis is consistent with the observation that left-right orientation is the main driving force behind early adolescent formation, intergenerational transmission, and life-course stability of party preferences in countries like the Netherlands (Percheron \& Jennings, 1981; Rico \& Jennings, 2015; Rekker et al., 2018). Interestingly, the analyses also revealed that ideological camps can be used to detect how some parties fall outside the regular pattern of electoral competition. For example, we found that sympathizers of anti-immigrant or radical right parties form a distinct class of their own, which cannot readily be connected to the other political parties.

Apart from providing more insight into the decision making process of individual voters and the stability and structured changes of consideration sets, the findings also shed some further light on electoral volatility. This is often interpreted as a signal of voters having unstable political orientations. It appears that electoral volatility may to a considerable extent be attributed to voters choosing a different party from the same consideration set in subsequent elections. As proposed by our two-stage model of electoral choice, this suggests that consideration sets are indeed rooted in stable political dispositions such as positions on core policy dimensions or ideological positions. Which party voters eventually choose from within their consideration set, may contrarily depend more on changeable factors such as leader evaluations, campaign coverage in the media, and strategic considerations. So there appears to be more stability in electoral preferences than high numbers of electoral volatility may suggest. 


\section{ACKNOWLEDGEMENTS}

We would like to thank Henrik Oscarsson and his colleagues from the University of Gothenburg for collecting and sharing the Swedish data used in this paper, as well as Laurens Klein Kranenburg, Peter Kanne and their colleagues from $I \& O$ Research in Enschede and Amsterdam for collecting and sharing the Dutch data. Furthermore, we are grateful to Jacob Sohlberg, Markus Steinbrecher, the anonymous reviewers of this journal, and all other colleagues who provided valuable feedback on earlier versions of this paper. This research did not receive any specific grant from funding agencies in the public, commercial, or not-for-profit sectors. 


\section{REFERENCES}

Alwin, D.F., Cohen, R.L., Newcomb, T.M., 1991. Political attitudes over the life span: the Bennington women after fifty years. University of Wisconsin Press, Madison.

Blais, A., Nadeau, R., 1996. Measuring strategic voting: A two-step procedure. Electoral Studies, 15 (1), 39-52.

Boije, E., Oscarsson, H., Oskarson, M., 2016. The 2014 CSM Campaign Panel Study report. The Swedish National Election Studies, Gothenburg.

Campbell, A., Converse, P.E., Miller, W.E., Stokes, D.E., 1960. The American Voter. New York: John Wiley \& Sons.

Dassonneville, R., Hooghe, M., 2011. Mapping electoral volatility in Europe. Conference paper at European Conference on Comparative Electoral Research, Sofia, Bulgaria.

De Vries, C.E., Rosema, M., 2009. Taking voters' consideration set into consideration: Modelling electoral choice in two stages. Conference paper at ECPR General Conference, Potsdam, Germany.

Drummond, A.J., 2006. Electoral volatility and party decline in Western democracies: 19701995. Political Studies, 54 (3), 628-647.

Fredén, A., Sohlberg, J., 2018. Insurance strategic considerations in coalition-oriented systems: A consideration set model approach. Electoral Studies, this issue.

Gensch, D., 1987. A two-stage disaggregate attribute choice model. Marketing Science, 6 (3), 223-231.

Howard, J.A., Sheth, J.N., 1969. The theory of buyer behaviour. New York: John Wiley.

Jennings, M.K., Markus, G.B., 1984. Partisan orientations over the long haul: Results from the three-wave political socialization panel study. American Political Science Review, 78 (4), 1000-1018.

Jungar, A., Jupskås, A.R., 2014. Populist Radical Right parties in the Nordic region: A new and distinct party family? Scandinavian Political Studies, 37 (3), 215-238.

Kaplan, D., 2008. An overview of Markov chain methods for the study of stage-sequential developmental processes. Developmental Psychology, 44 (2), 457-467.

Karlsen, R., Aardal, B., 2016. Political values count but issue ownership decides? How stable and dynamic factors influence party set and vote choice in multiparty systems. International Political Science Review, 37 (2), 261-276. 
Kleinnijenhuis, J., Maurer, M., Kepplinger, H.M., Oegema, D., 2001. Issues and personalities in German and Dutch television news: patterns and effects. European Journal of Communication, 16 (3), 337-359.

Lijphart, A., 2012. Patterns of democracy: Government forms and performance in thirty-six countries. Second edition. New Haven: Yale University Press.

Mair, P., 2008. Electoral volatility and the Dutch party system: A comparative perspective. Acta Politica, 43 (2), 235-253.

Mayer, S.J., Schultze, M., 2018. The effects of political involvement and cross-pressures on multiple party identifications in multi-party systems - evidence from Germany. Journal of Elections, Public Opinion and Parties, DOI: 10.1080/17457289.2018.1466785

Miller, W.E., 1991. Party identification, realignment, and party voting: Back to the basics, American Political Science Review, 85 (2), 557-568.

Moral, M., Zhirnov, A., 2018. Issue voting as a constrained choice problem. American Journal of Political Science, 62 (2), 280-295.

Oscarsson, H., Gilljam, M., Granberg, D., 1997. The concept of party set: A viable approach or just another way to slice the same cheese? Conference paper at Swedish Political Science Association, Uppsala, Sweden.

Oscarsson, H., Oskarson, M., 2018. Sequential vote choice: A consideration set model of heterogeneous decision processes for party choice. Electoral Studies, this issue.

Oscarsson, H., Rosema, M., 2018. Consideration set models of electoral choice: theory, method, and application. Electoral Studies, this issue.

Oskarson, M., Oscarsson, H., Boije, E., 2016. Consideration and choice: Analyzing party choice in the Swedish European election 2014. Scandinavian Political Studies, 39 (3), 242-263.

Paternoster, R., Brame, R., Mazerolle, P., Piquero, A., 1998. Using the correct statistical test for the equality of regression coefficients. Criminology, 36 (4), 859-866.

Percheron, A., Jennings, M.K., 1981. Political continuities in French families: A new perspective on an old controversy. Comparative Politics, 13 (4), 421-436.

Reinecke, J., 2006. Longitudinal analysis of adolescent's deviant and delinquent behaviour. Methodology: European Journal of Research Methods for the Behavioral and Social Sciences, 2 (3), 100-112.

Rekker, R., 2016. The lasting impact of adolescence on left-right identification: cohort replacement and intracohort change in associations with issue attitudes. Electoral Studies, 44, 120-131. 
Rekker, R., Keijsers, L., Branje, S., Meeus, W., 2015. Political attitudes in adolescence and emerging adulthood: Developmental changes in mean level, polarization, rank-order stability, and correlates. Journal of Adolescence, 41, 136-147.

Rekker, R., Keijsers, L., Branje, S., Meeus, W., 2018. The formation of party preference in adolescence and early adulthood: How and when does it occur in the multiparty context of the Netherlands? Young, 27 (1), 1-21.

Rico, G., Jennings, M. K., 2015. The formation of left-right identification: Pathways and correlates of parental influence. Political Psychology, 37 (2), 237-252.

Roberts, J.H., Lattin, J.M., 1991. Developing and testing of a model of consideration set composition. Journal of Marketing Research, 28 (4), 429-440.

Roberts, J.H., Lattin, J.M., 1997. Consideration: Review of research and prospects for future insights. Journal of Marketing Research, 34 (3), 406-410.

Rooduijn, M., 2014. Vox populismus: a populist radical right attitude among the public? Nations and Nationalism, 20 (1), 80-92.

Rosema, M., 2004. The sincere vote: A psychological study of voting. Unpublished Ph.D. dissertation. Leiden: Leiden University.

Rosema, M., 2015. Voters choose in stages: A consideration set model of voting. Conference paper at ECPR General Conference, Montréal, Canada.

Schmitt-Beck, R., Partheymüller, J., 2016. A two-stage theory of discussant influence on vote choice in multiparty systems. British Journal of Political Science, 46 (2), 321-348.

Sears, D.O., Funk, C.L., 1999. Evidence of the long-term persistence of adults' political predispositions. The Journal of Politics, 61 (1), 1-28.

Shocker, A.D., Ben-Akiva, M., Boccara, B., Nedungadi, P., 1991. Consideration set influences on consumer decision-making and choice: issues, models, and suggestions. Marketing Letters, 2 (3), 181-197.

Simon, H.A., 1955. A behavioral model of rational choice. The Quarterly Journal of Economics, 69 (1), 99-118.

Steenbergen, M., Willi, T., 2018. What choice sets can teach us about electoral competition: A two hurdle model. Electoral Studies, this issue.

Steinbrecher, M., Schoen, H., 2018. Channelling attention and choice? Examining effects of consideration sets on electoral decision-making. Electoral Studies, this issue.

Thomassen, J., Ed., 2005. The European voter: A comparative study of modern democracies. Oxford: Oxford University Press.

Tillie, J.N., Fennema, M., 1998. A rational choice for the extreme right. Acta Politica, 33 (3), 223-249. 
Tversky, A., 1972. Elimination by aspects: A theory of choice. Psychological Review, 79 (4), 281-299.

Van der Eijk, C., Franklin, M.N., et al., 1996. Choosing Europe? The European electorate and national politics in the face of the union. Ann Arbor, MI: Michigan University Press.

Van der Eijk, C., Franklin, M.N., 2009. Elections and voters. Basingstoke: Palgrave MacMillan.

Van der Eijk, C., Schmitt, H., Binder, T., 2005. Left-right orientations and party choice. In The European voter: A comparative study of modern democracies (Thomassen, J., ed., pp. 166-190), Oxford: Oxford University Press.

Van der Meer, T.W.G., van Elsas, E., Lubbe, R., van der Brug, W., 2012. Kieskeurige kiezers: Een onderzoek naar de veranderlijkheid van Nederlandse kiezers, 2006-2010. Amsterdam: University of Amsterdam.

Van der Meer, T.W.G., van Elsas, E., Lubbe, R., van der Brug, W., 2015. Are volatile voters erratic, whimsical or seriously picky? A panel study of 58 waves into the nature of electoral volatility (the Netherlands 2006-2010). Party Politics, 21 (1), 100-114.

Vassik, K., Solvak, M., Ehin, P., 2016. More choice, higher turnout? The impact of consideration set size and homogeneity on political participation. Journal of Elections, Public Opinion and Parties, 26 (1), 78-95.

Wilson, C.J., 2008. Consideration sets and political choices: A heterogeneous model of vote choice and sub-national party strength. Political Behavior, 30 (2), 161-183. 
Figure 1. A two-stage model of electoral choice and level of stability

Consideration Stage

e.g., ideological proximity
Choice Stage

e.g., media attention, leader evaluations, strategic considerations

\begin{tabular}{|c|c|c|c|}
$\begin{array}{c}\text { Values and Identity } \\
\text { Strong } \\
\text { life-course stability }\end{array}$ & $\begin{array}{c}\text { Consideration Set } \\
\text { Intermediate } \\
\text { life-course stability }\end{array}$ & $\begin{array}{c}\text { Voting Intention } \\
\text { Weak } \\
\text { life-course stability }\end{array}$ \\
\cline { 2 - 3 }
\end{tabular}


Figure 2. Stability of consideration sets among voters across a one-year period

\section{Sweden}

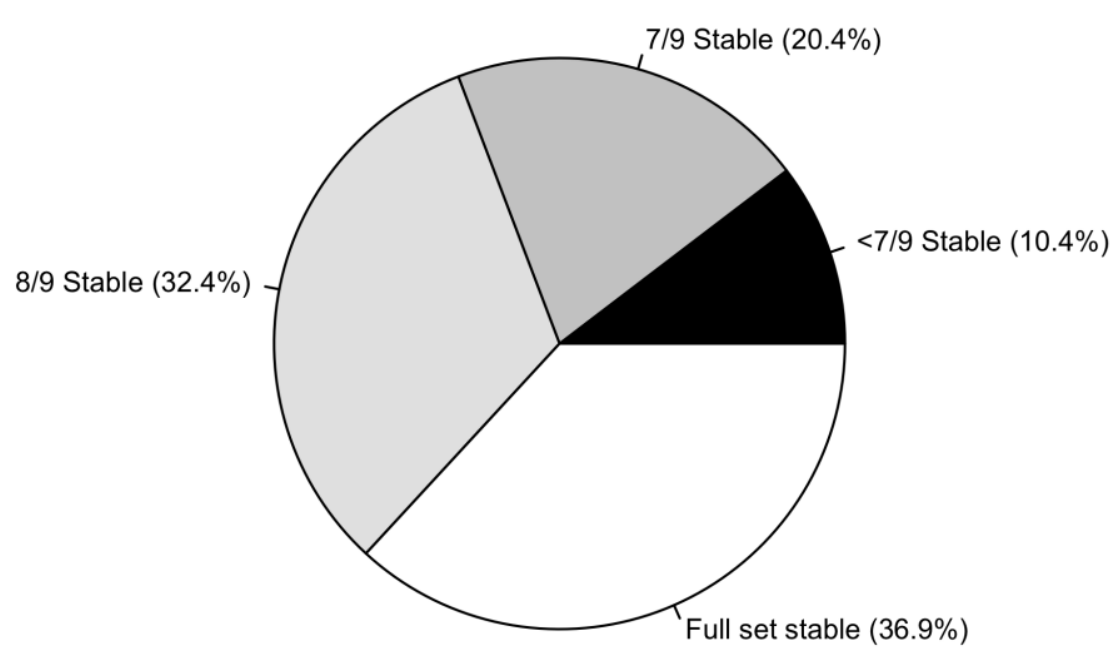

\section{The Netherlands}

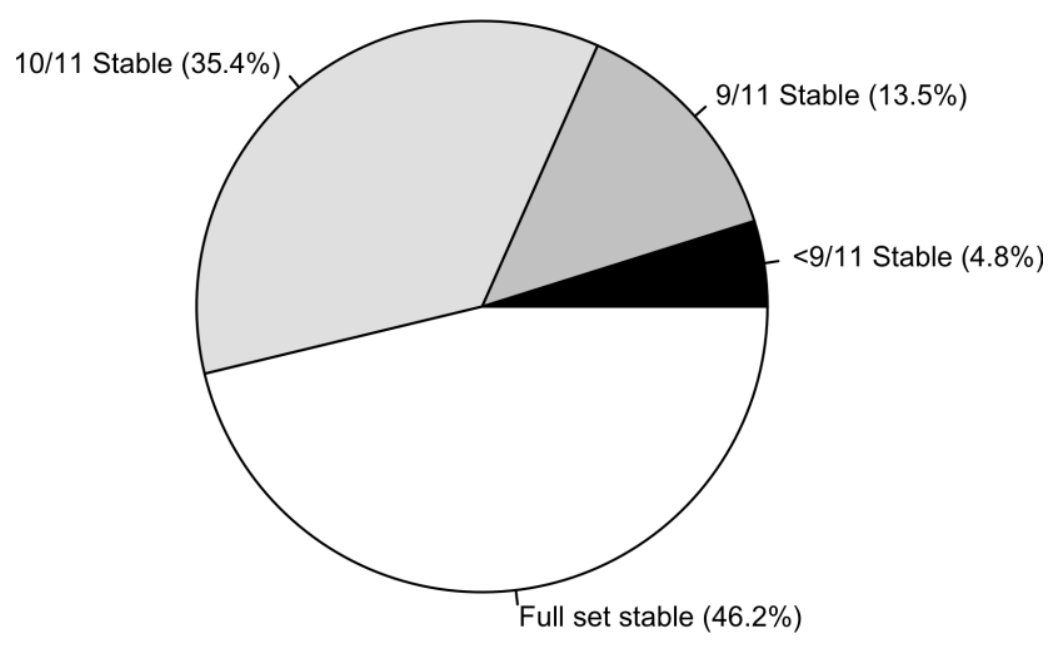


Figure 3. Classes of consideration sets in Sweden: three ideological camps
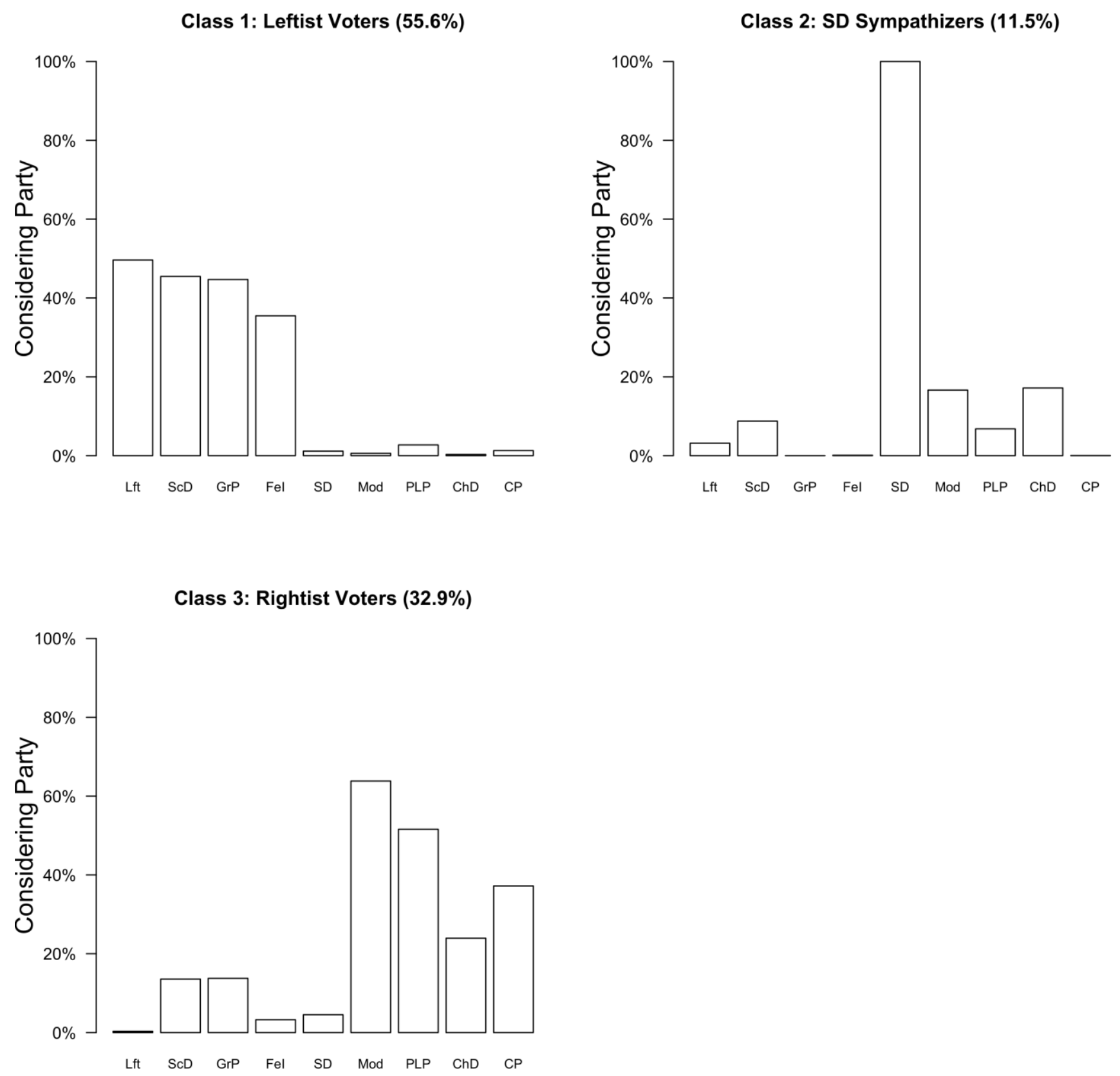
Figure 4. Classes of consideration sets in the Netherlands: four ideological camps

Class 1: Leftist Voters (50.1\%)

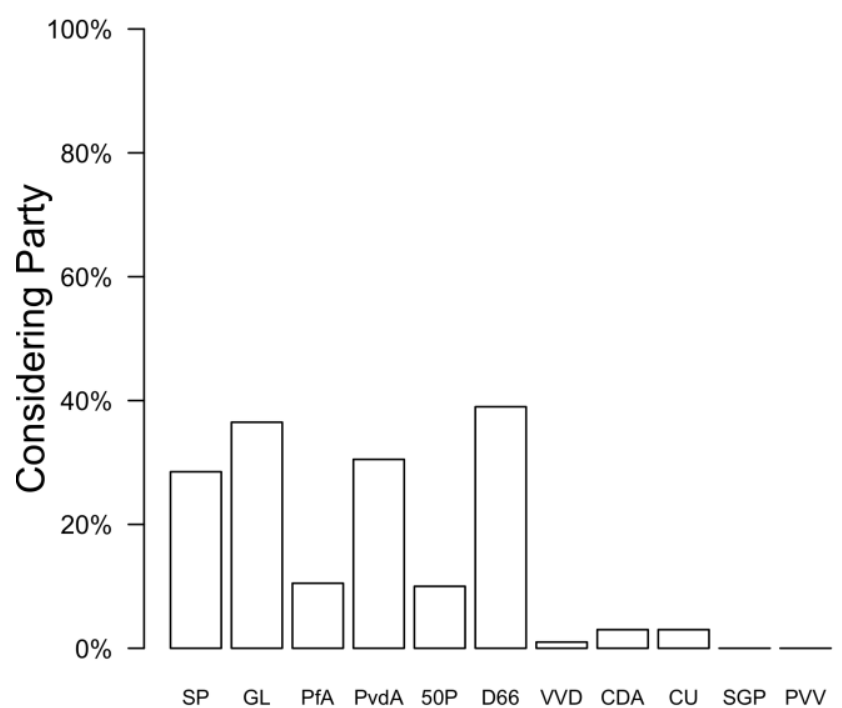

Class 3: Christian Voters (19.5\%)

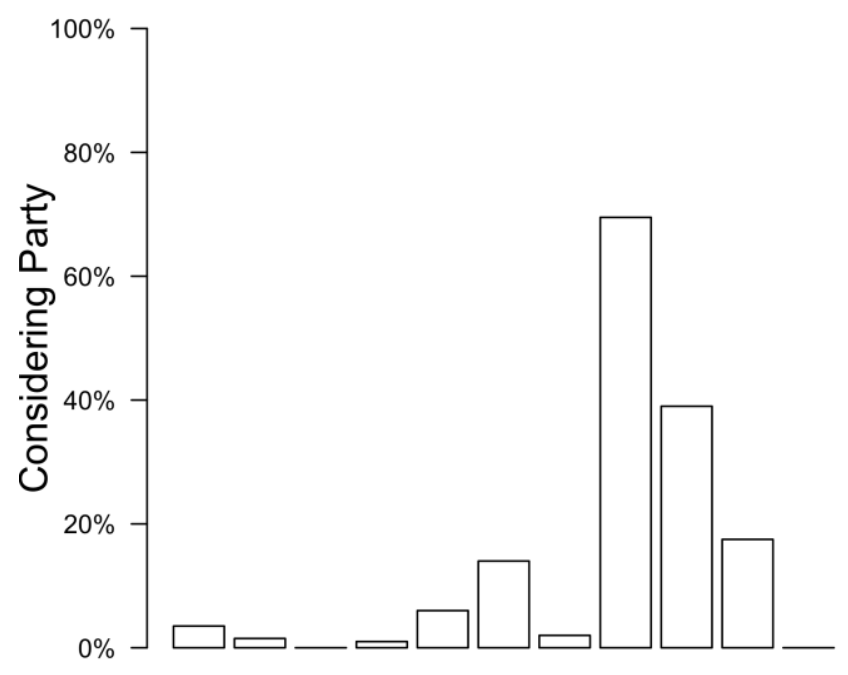

SP GL PfA PvdA 50P D66 VVD CDA CU SGP PVV
Class 2: PVV Sympathizers (12.8\%)

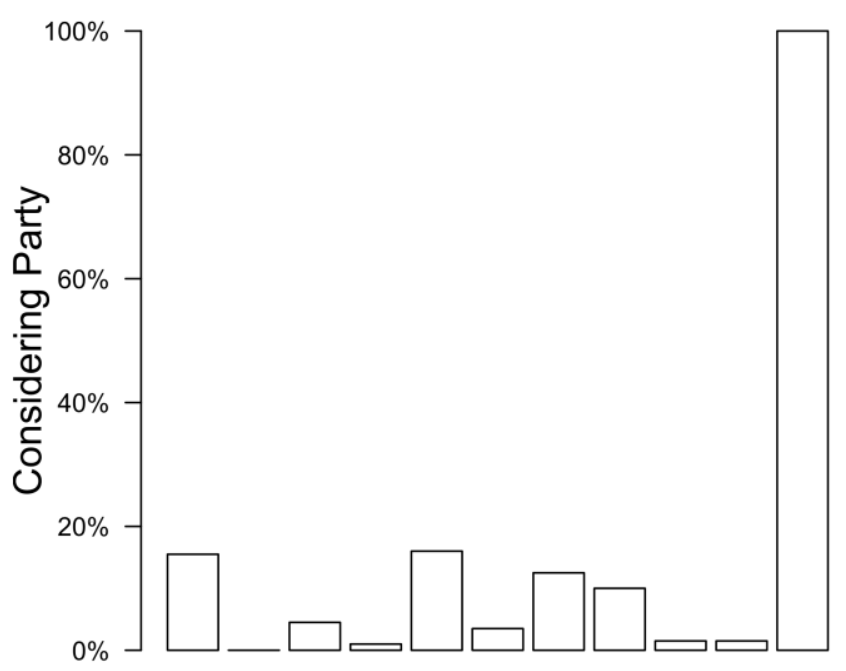

SP GL PfA PvdA 50P D66 VVD CDA CU SGP PVV

Class 4: Rightist Voters (17.6\%)

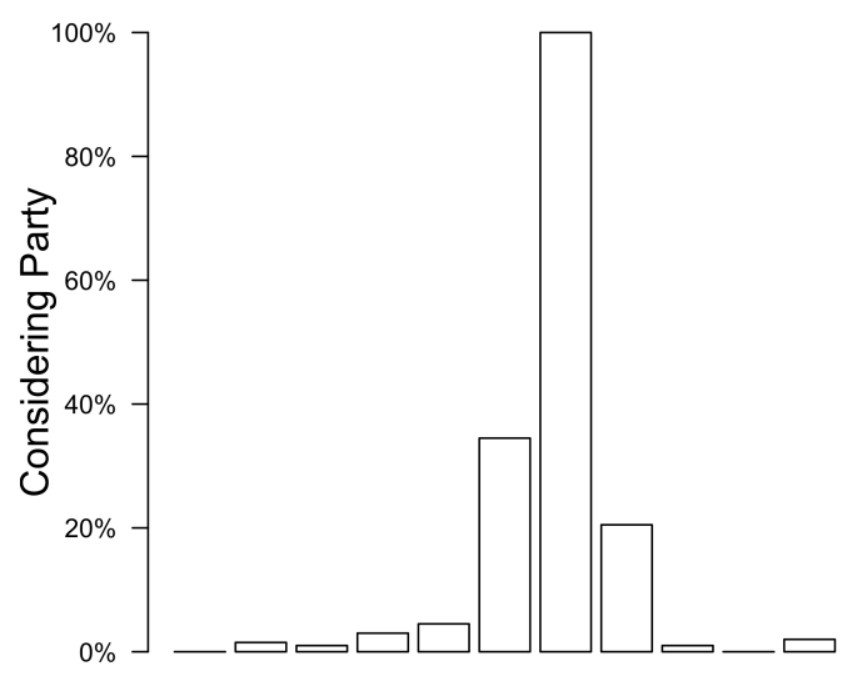

SP GL PfA PvdA 50P D66 VVD CDA CU SGP PVV 
Table 1. Size of consideration sets and stable number of parties

\begin{tabular}{lcccccccc}
\hline & & \multicolumn{2}{c}{ Sweden } & \multicolumn{4}{c}{ The Netherlands } \\
Number of parties & Considered & SE & Stable & SE & Considered & SE & Stable & SE \\
\hline Distribution & & & & & & & & \\
0 & $3.8 \%$ & 0.1 & $0.0 \%$ & 0.0 & $9.1 \%$ & 0.3 & $0.0 \%$ & 0.0 \\
1 & $31.3 \%$ & 0.4 & $0.0 \%$ & 0.0 & $56.4 \%$ & 0.6 & $0.0 \%$ & 0.0 \\
2 & $35.3 \%$ & 0.4 & $0.0 \%$ & 0.0 & $24.4 \%$ & 0.5 & $0.0 \%$ & 0.0 \\
3 & $21.7 \%$ & 0.3 & $0.1 \%$ & 0.0 & $8.2 \%$ & 0.3 & $0.0 \%$ & 0.0 \\
4 & $6.6 \%$ & 0.1 & $0.5 \%$ & 0.0 & $1.5 \%$ & 0.2 & $0.0 \%$ & 0.0 \\
5 & $0.9 \%$ & 0.0 & $2.4 \%$ & 0.1 & $0.2 \%$ & 0.1 & $0.0 \%$ & 0.0 \\
6 & $0.2 \%$ & 0.0 & $7.4 \%$ & 0.2 & $0.1 \%$ & 0.0 & $0.1 \%$ & 0.0 \\
7 & $0.0 \%$ & 0.0 & $20.4 \%$ & 0.4 & $0.0 \%$ & 0.0 & $0.7 \%$ & 0.1 \\
8 & $0.0 \%$ & 0.0 & $32.4 \%$ & 0.4 & $0.0 \%$ & 0.0 & $4.0 \%$ & 0.3 \\
9 & $0.0 \%$ & 0.0 & $36.9 \%$ & 0.5 & $0.0 \%$ & 0.0 & $13.5 \%$ & 0.5 \\
10 & & & & & $0.0 \%$ & 0.0 & $35.4 \%$ & 0.8 \\
11 & & & & & $0.0 \%$ & 0.0 & $46.2 \%$ & 0.8 \\
Average & 2.0 parties & 0.0 & 7.9 parties & 0.0 & 1.4 parties & 0.1 & 10.2 parties & 0.1 \\
\hline
\end{tabular}


Table 2. Stability of four constructs across a one-year period

\begin{tabular}{|c|c|c|c|c|c|c|c|}
\hline \multirow[b]{2}{*}{ Stability of } & \multicolumn{3}{|c|}{ Sweden } & \multicolumn{3}{|c|}{ The Netherlands } & \multirow{2}{*}{$\begin{array}{l}\text { Average } \\
\text { Estimate }\end{array}$} \\
\hline & Estimate & $\mathrm{SE}$ & $\mathrm{N}$ & Estimate & $\mathrm{SE}$ & $\mathrm{N}$ & \\
\hline Voting intention & $67.6 \%$ & 0.5 & 9854 & $82.7 \%$ & 0.6 & 3884 & $75.2 \%$ \\
\hline Consideration & $73.1 \%$ & 0.3 & 11022 & $87.9 \%$ & 0.4 & 4032 & $80.5 \%$ \\
\hline Full consideration set & $36.9 \%$ & 0.5 & 11351 & $46.2 \%$ & 0.8 & 4032 & $41.6 \%$ \\
\hline Ideological camp & $87.0 \%$ & 0.3 & 11351 & $86.1 \%$ & 0.5 & 4032 & $86.6 \%$ \\
\hline
\end{tabular}


Table 3. Statistics to determine the number of classes in a Latent Transition Analysis (LTA)

\begin{tabular}{lcccc}
\hline Country & Classes & BIC & VLMR p & Entropy \\
\hline Sweden & 2 & 249440.344 & $<.001$ & 0.61 \\
& 3 & 244417.423 & $<.001$ & 0.70 \\
& 4 & 242361.501 & $<.001$ & 0.59 \\
& 5 & 240727.541 & $<.001$ & 0.62 \\
\hline The Netherlands & 2 & 108756.124 & $<.001$ & 0.47 \\
& 3 & 106716.430 & $<.001$ & 0.57 \\
& 4 & 104917.290 & $<.001$ & 0.65 \\
& 5 & 103906.496 & $<.001$ & 0.63 \\
\hline
\end{tabular}


Table 4. The extent to which voting intentions match ideological camps, consideration sets, and voting intentions of one year earlier

\begin{tabular}{|c|c|c|c|c|c|}
\hline \multicolumn{6}{|l|}{ Sweden } \\
\hline \multirow[b]{2}{*}{ Voting intention in second wave } & \multicolumn{3}{|c|}{$\underline{\text { Ideological Camp }}$} & \multirow[b]{2}{*}{$\begin{array}{c}\text { Party in } \\
\text { Consideration Set }\end{array}$} & \multirow[b]{2}{*}{$\begin{array}{c}\text { Party as } \\
\text { Voting Intention }\end{array}$} \\
\hline & $\begin{array}{l}\text { Leftist } \\
\text { Voters }\end{array}$ & $\begin{array}{c}\text { SD } \\
\text { Sympathizers }\end{array}$ & $\begin{array}{l}\text { Rightist } \\
\text { Voters }\end{array}$ & & \\
\hline Left Party & $99.6 \%$ & $0.3 \%$ & $0.1 \%$ & $96.0 \%$ & $81.5 \%$ \\
\hline Social Democrats & $92.4 \%$ & $0.7 \%$ & $6.9 \%$ & $87.9 \%$ & $66.0 \%$ \\
\hline Green Party & $94.3 \%$ & $0.0 \%$ & $5.7 \%$ & $95.9 \%$ & $77.3 \%$ \\
\hline Feminist Initiative & $98.2 \%$ & $0.3 \%$ & $1.5 \%$ & $91.1 \%$ & $74.5 \%$ \\
\hline Sweden Democrats & $11.8 \%$ & $72.6 \%$ & $15.6 \%$ & $83.0 \%$ & $76.6 \%$ \\
\hline Moderates & $8.0 \%$ & $2.6 \%$ & $89.4 \%$ & $89.0 \%$ & $73.5 \%$ \\
\hline People's Liberal Party & $14.2 \%$ & $1.5 \%$ & $84.4 \%$ & $89.5 \%$ & $73.4 \%$ \\
\hline Christian Democrats & $9.6 \%$ & $8.0 \%$ & $82.4 \%$ & $77.2 \%$ & $55.6 \%$ \\
\hline Centre Party & $13.7 \%$ & $0.7 \%$ & $85.6 \%$ & $68.7 \%$ & $43.6 \%$ \\
\hline Weighted average & & & & $88.1 \%$ & $71.6 \%$ \\
\hline
\end{tabular}

The Netherlands

$\underline{\text { Ideological }}$ Camp

\begin{tabular}{lccccc} 
Voting intention in second wave & $\begin{array}{c}\text { Leftist } \\
\text { Voters }\end{array}$ & $\begin{array}{c}\text { PVV } \\
\text { Sympathizers }\end{array}$ & $\begin{array}{c}\text { Christian } \\
\text { Voters }\end{array}$ & $\begin{array}{c}\text { Rightist } \\
\text { Voters }\end{array}$ & $\begin{array}{c}\text { Party as } \\
\text { Consideration Set }\end{array}$ \\
\cline { 4 - 6 } Voting Intention
\end{tabular}

